\title{
Memory in Old Age: Current Scenario in India
}

\author{
Dr. K. Lalitha ${ }^{1}$, Dr. D. Jamuna ${ }^{2}$
}

\section{ABSTRACT}

One of the common concerns of older people is the complaint that their memory was not as good as it was. Empirical studies on memory have highlighted that memory losses are not uncommon in any age. According to statistics, 70\% of older adults report that they have memory problems, but objective tests are needed to determine if they have mild cognitive impairment, which is also known as benign senescent forgetfulness (AAMD) and early dementia. Mild cognitive impairment is basically a transitional stage between normal aging and Alzheimer's disease. Studies show that $17 \%$ to $34 \%$ of elderly people have mild cognitive impairment. One of the significant areas of contemporary gerontological researches is planning of systematic interventions in improving memory. This article focuses on the research carried out on memory and old age in India and discusses the need for further research.

Keywords: Memory, Researches memory in India, current scenario

Memory is defined as a recall of stored information on demand. An item of memory was thought of as a single unit with an identifiable place of residence somewhere in the brain that could be recalled when necessary. Earlier, memory used to be regarded as a structure, now it is seen as a process (Howard, 2004). Memory is such a pervasive aspect of our daily lives that we take it for granted. Memory is the yardstick with which society judges whether a person is socially intact or not. We depend on our memory systems to carry out every day plans of our lives. Human memory systems truly are remarkable when you think of how much information we put into our memories and how much we must store and how much we must retrieve to perform all of life's activities (Willingham, 2004).

Research over the past decades shows that the mind constantly adjusts its way of doing things and compensates nicely for many losses in efficiency. The brain is almost infinitely plastic, containing many more neurons than we can use. If one neuron fails, those nearby can take on its load. There is solid evidence that determination in mental functions can actually be reversed probably with animals and humans (Psychology Today, 1993).

\footnotetext{
${ }^{1}$ Asst. Professor, Dept. of Psychology, Y.V. University, Kadapa

2 Professor, Dept. of Psychology, S.V. University, Tirupati

(C) 2015 I K Lalitha, D Jamuna; licensee IJIP. This is an Open Access Research distributed under the terms of the Creative Commons Attribution License (http://creativecommons.org/licenses/by/2.0), which permits unrestricted use, distribution, and reproduction in any Medium, provided the original work is properly cited.
} 


\section{Memory in Old Age: Current Scenario in India}

But there are two types of such losses during later part of life. One of this is normal, age related, gradual decline called Age Associated Memory Decline (AAMD) the other is disease associated memory loss i.e., dementia as happens in the case of Senile Dementia of Alzheimer's Type (SDAT) (Lalitha, 2000, 2005).

Memory researchers have long focused on three general steps i.e., memory is the retention of information over time through encoding, storage, retrieval (Smith, 1996).

Older citizens often lament what they perceive as deteriorating memory (Carol \& Rabbit, 1991; Wythe \& Anderson, 1997). Several studies on memory and aging have reported age related decline, whereas other studies have failed to find unambiguous age related changes (Park, 1997). Age related differences in memory are influenced by an interaction of multiple factors (Salthouse

\& Skovernek, 1992). For instance, the researches in the area of memory have interpreted the findings on age differences in working memory as being due to greater susceptibility to interference as a function of age (Kausler, 1994; Perlmutter, 1986). Such interference may have a direct effect on the storage and retrieval stages of information processing. Despite these observations, the attempts to demonstrate directly the effects of interference on memory have not given consistent results. Despite these observed inconsistencies it is generally believed that there is a decline in memory function in many individuals as measured through various tests, with advancing age. But nature and quantum of change differs with the test being used.

The researches on memory and ageing indicate memory processing as a potential source of age differences (Park et al., 1996; Salthouse, 1994). Due to paucity of evidence on age differences on how information is organized in storage, most researchers have examined encoding and retrieval as sources of age differences. Regardless of whether the cause is physiological, biochemical, motivational or due to other non-cognitive factors, there are differences in memory functioning among the young and the old. The very brightest older person seems to show both relatively and absolutely less loss, but, in time, even these individuals perform less well than when they were young. Since the amount of loss occurring with progressive age depends upon the type of material used and the kind of learning and memory involved, it is difficult to conclude in a general way of presence or absence of memory impairment with advancing age. Neither using a single test nor a combination of various tests is adequate to draw generalized inferences on memory in the aged. There appears to be some specificity of age change. This suggests a need to use tests for specific functions. In recent years there has been an emphasis among Western researchers, on the study of memory types to study of memory deficits especially age associated dementia's and cognitive interventions to deal with them (Howard, 2004). But the review of researches in the area of geropsychology shows that very few scientific studies are available on cognitive aspects of ageing in Asia compared to West (Lalitha, 2000, 2005; Ramamurti \& Jamuna, 1984, 1993, 1995). Hess and Hinson (2006) in their study on adults 24-86 years found that adults in their 60s exhibited weak effects consistent with the operation of stereotype threat, whereas middle-age adults exhibited a contrast effect in memory performance, suggestive of stereotype lift. Beliefs about aging and memory were also affected by stereotypic 


\section{Memory in Old Age: Current Scenario in India}

information, and older adults' changed beliefs were more important in predicting performance than was exposure to stereotype-based information alone. The volume of research output on various aspects of memory carried out on western populations is amazing (e.g., Cavanaugh, 1997; Cavanaugh \& Balnchar-Fields, 2002; Kausler, 1994; Poon, 1985; Whitbourne, 2005).

Memory is a function which bears many facets. Empirical evidence is plenty that points to the differential decline in these facets of memory. A large number of empirical studies have demonstrated that younger subjects perform better than the older subjects with regard to memory. Though many elderly experience relatively little difficulty in remembering some of their early life events (e.g., events of their childhood) yet they may find it difficult to learn and retain new material. Bromley (1958) and Gilbert (1941) reported that learning and memory of recent material is complex and a marked decline in memory occurs especially in those aspects calling for the formation of completely new associations, the interpretation of new inputs as well as in retention of newly learnt material. While accepting the fact of significant age differences in memory performance, one must understand the complex nature of memory and the multifarious factors determining the size of the age differences. Due to its complexity, scientists continue to strive to unravel the intricacies of human memory. It is considered as one of the important and fascinating areas of Gero psychological research as evident from the observation that 34 percent of the published articles in the two journals viz., Psychology and Aging, and the Journal of Gerontology: Psychological Sciences, were in the area of memory and ageing (Birren \& Schaie, 1996).

\section{Researches on Memory and Old age in India}

Memory, of all types, plays a significant role in one's lives. Memory decline in the elderly who are already handicapped in several ways has special negative implications for them in going about their normal daily activities and compound their dependency. Man's present and prospective activities in his day to day life are organized on the basis of the past experience. Therefore, memory plays a critical role in the day today functioning of the elderly. When memory is upset as it happens in the case of certain pathological conditions like Alzheimer's disease (where the individual progressively loses his memory), life gets disorganized, nonfunctional and unable to progress. Therefore, the study of memory occupies a significant position in the field of ageing. Indian researches carried out in the area of memory and cognition are not many (Ramamurti \& Jamuna, 1984, 1993; 1995).

Some studies are available on memory and other cognitive aspects in the Indian elderly (Dubey, 1996; Khan \& Khan, 2002; Kohli et. al., 1992; Pershad, 1979a, 1979b; Ramamurti, 1978, 1990; Sharma, et al., 1992; Verma, \& Pershad, 1996). Studies reported a general decline in cognitive function in later years.

Pershad (1979) investigated whether younger subjects aged 20-40 yrs. and elderly subjects aged 41-70 yrs. differed with regard to acquisition, retention recall (forgetting), and learning

dissimilar pairs of words. Both retention and retentive recall were poor in elderly subjects, and 


\section{Memory in Old Age: Current Scenario in India}

both groups differed significantly with regard to initial learning on a paired-associate tasks, but gains from trial to trial were not significantly different.

Pershad and Wig (1977) developed the PGI Memory Scale for Memory Testing in the elderly subjects (Pershad, 1976; Pershad \& Wig, 1976) with two-sub tests i.e., "Delayed recall” and "Verbal retention for dissimilar pairs". These two were selected because they have been demonstrated to be quite simple and acceptable to the general population in the Indian context and they were also found to have low correlation with intelligence test scores (Pershad, 1976). The same scale was administered (Pershad, 1979a) on young and elderly subjects concluded that the retention and retentive recall both are affected by the aging process, and the retentive recall is more affected. Pro-active interference is not found to be significantly different in the two groups. Younger and elder subjects differ with regard to initial learning, but benefit from trial to trial is not significantly different. Prior to this, Isaacs and Aktar (1972) developed “The Set Test” to measure the mental functions of the normal elderly and one that is not dependent on the subject's cultural and educational background. It is good for use in clinical and epidemiological setting (Anuradha et. al., 1991) and for normal elderly (Dubey \& Verma, 1991) while assessing memory in the aged.

Using a battery of psychological tests on Indian elderly (Verma et. al., 1992) found significant intercorrelations among the tests but of moderate degree at best, suggesting that they are contributing their share more or less independently to the mental status (evaluation) of the elderly. Same tests were administered (by Kohli et al., 1992) on depressive elderly (55+) and it was found that they not only showed higher depression scores, but also low mental efficiency, general orientation, memory and general information level than normal aged.

Language aging is a natural outgrowth of an area of research called Geriatric Psycholinguistics. Sharma et. al., (1992) emphasized the importance of study of language in the elderly. They found an age related decline. They strongly recommend in-depth study of the elderly adult's language and an examination of features, which can be accounted for due to age related changes in the elderly adults. Agrawal and Kumar (1992) in a 3 phase study with 20-80yr. old males and females (20-65yr) studied gender differences in everyday memory problems, the effect of age, sex, task complexity and sensory modality on the speed of information processing and the explicit role of factors as causes of cognitive changes with increasing age. Analyses showed that significant changes occurred with age in everyday memory capacity. Older and aged males showed a decrease in memory problems, while females showed an increment in memory problems.

Dubey (1996) developed Cognitive Dysfunctioning Scale, which is applicable in clinical settings of Neurology and Psychiatry as a routine mental examination. It evaluates higher mental functioning. Gupta and Kaur (1996) in a study of episodic memory in young and elderly found that elderly females performed significantly better than elderly males in inferential processing. 
The overall findings of age deficit in information processing are attributed to general age related slowing and reduced working memory and attentional capacity (Gupta \& Srivastava, 2000).

In the logical information task the subject is expected to recall the given material in the same sequence. The results on memory for logical information suggest that the mean ideas recalled by the subjects in the older age groups (80+) actually decreased with age. The mean number of ideas generated on a given passage was 6.52 in 80-89 age group, but it was 12.14 in 60-69 group. It is relevant to consider some observations made on passage recall. The presentation of stimuli and organization of information are important factors in interpreting differences in overall performance on ideas recalled from a passage (Jamuna et al., 1999; Lalitha, 2001, 2005).

In digit span tasks, the subjects are required to recall the digits in a forward manner (Forward digit span) and digits in the reverse order (Backward digit span). The overall trends suggest that there is a decrement in the memory performance of forward digit span and backward digit span. The results showed age related deficit in memory for backward digit span tasks. It was found to be greater than that of the forward span (Jamuna et al., 1999; Lalitha, 2002, 2005). In the letter span task also the elderly subjects were asked to reproduce the same span of letters. The mean letter span in the sample was found to be 3.84 in 60-69; 2.58 in 70-79; and 1.91 in 80-89 years. The general trend in the performance in working memory indicates that there is a deterioration of performance with increasing age. It is clearly manifested in the comparison of 60-69 with 80-89 age-groups (Jamuna et al., 1999; Lalitha, 2000, 2005).

The results on working memory and gender differences show that males were found to perform better than females in all the sub-facets without exception. The locality trends suggest that the urban elderly have performed better than the rural; the more educated performed better than the less educated. In the Personal current information and Orientation tasks it was found that youngold, male, urban, those with education those who are with spouse showed better performance, compared to their counterparts. In the Mental control tasks it is evident from the data that the mean scores on mental control decreased with increasing age. (Jamuna et al., 1999; Lalitha, 2000, 2005).

In word association, there are negligible differences in all the sub-groups. The trends in the performance on semantic memory indicate that the older adults showed slower processing than younger groups in all the stimulus conditions. In the light of this observation it is relevant to mention some of the findings reported in the area of semantic memory research (Jamuna et al., 1999; Lalitha, 2000, 2005). The trends on verbal memory indicate that the oldest-old, the female elderly, the rural elderly and those without formal education, and those who are widowed performed poorer than their other counterparts (Jamuna et al., 1999; Lalitha, 2000, 2005). 


\section{Memory in Old Age: Current Scenario in India}

The age decline in elderly adults may be due to a production deficiency or performance decrement generally due to lack of practice in imaginal mediators, once they are out of touch with formal educational settings. In fact many studies stated that if production deficiency is involved, the age related paired associate learning should be largely overcome through the effective use of instructions and training. Elderly persons do begin to use imaginal mediators particularly after the practice on a number of paired associates lists. Greater age deficits were observed in spatial memory than in verbal working memory but provide no evidence of an age deficit in susceptibility to interference by secondary tasks. Several studies indicated that hard associates and visual reproductions were found to decline in later life (Lalitha, 2001).

As mentioned by the researchers probably the associative connections that exist between words could be altered or could be lost with age. This adversely affects the lexicon's organization. As a result, the distance between related words could increase or decrease and inturn there will be a change in the meanings of various words. However, supportive evidence is still needed on this. The findings on age differences (i.e., 80-89 performed the tasks poorly than 60-69) is consistent with the notion that the ability to allocate capacity in working memory to more than one task decreases with age. Considering the immediate recall of digits, ideas and letters in this facet, repeating items over and over works well (for e.g., digits, words) if one only needs to keep information in mind for a relatively brief period through making connections with information already in memory. It is relevant to discuss an important point on age differences in the speed of efficiency as reported in several information processing models. As per the information processing model, control or computational processes operate roughly in a similar way for young and old. But the individual differences are exhibited in the efficiency and speed of processing.

Cognitive failure was negatively related to the measures of intelligence and I-E control and positively relates to anxiety (Dwivedi, 1988; Dwivedi \& Misra, 1991; Lalitha, 2009). In contrast, the measure of memory beliefs yielded a positive relationship with internal control and scores on standard progressive matrices and negative relationship with external control and anxiety. These findings implicate that memory beliefs are importantly linked with personality and intellectual functions.

Studies on socio-demographic correlates of memory among older persons, (Jamuna \& Ramamurti, 2000; Jamuna et al., 1999; Lalitha, 2000) found that the variable education was the main predictor of the performance in various facets of memory. In all the cases, education was found to be an important contributor to the explained variance. Age found to be an important predictor of performance in the facets of working memory (viz., logical information, memory for digit span and word span). Examination of mental control tasks revealed that performance was poor in females than male elderly, rural than those of urban, less educated than those of more educated, widowed than non-widowed. It is reported that on memory for mental control tasks, older persons often experience difficulties in understanding and remembering spoken and written language (Jamuna et al., 1999; Lalitha, 2000, 2005). 


\section{Memory in Old Age: Current Scenario in India}

Remote memory was better in the 60-69 age group than in 70-79 and 80-89 groups. The subjects living in urban areas, male, those with more than high school education and with college education and those who are living with spouses performed better than their other counterparts (Jamuna et al., 1999; Lalitha, 2000, 2005). Especially while interpreting the age decrements in remote memory performance, one needs to be careful because it is often hard to know whether the episode that the subject recalls is from the ancient. Failure to recall past events might be either due to an inability to retrieve the information or due to a failure in the first instance to register it strongly. This issue needs to be considered especially while comparing elderly with young subjects.

While interpreting the autobiographical memory, one must take into account socio-cultural and developmental determinants of memo ability and internal mechanisms of the cognitive system. The age differences in episodic recall, may be due to age related differences in the executive skills required for optimal performance on the given test. Over time, the memory for past events becomes less vivid and loses detail (Cohen, 1996). Information that is stored and not accessed from remote memory appears to become increasingly difficult to retrieve, with the passing years. This apparent truism is not supported by data on remote memory.

It is generally believed that subjects with moderate to high income will have certain benefits and facilities. In a country like India where majority of the elderly are living below or just above the subsistence level, the economic status of an incumbent plays a pivotal role in well being. Also, the economically sound persons have comparatively better access to educational facilities and experiences of modern technological advancement. This would put them at a decided advantage compared to those who are economically less sound (Lalitha, 2000, 2005).

\section{Role of Psycho-Social Factors and Memory}

The possible relationships between memory and some psychological factors are, perhaps more complex, but intriguing nonetheless. The studies on adult intelligence and personality or self belief variables (for e.g., self-esteem, internal and external locus, mental health and social supports) suggest that close or possible inter dependent relationship is obvious (Lalitha, 2000; Lalitha \& Jamuna, 2004a).

Among the psychological variables in association with different facets of memory, the highly correlating variables were self-rated memory, self-esteem and locus of control with the exception of logical information and the free word association. The moderately (and negatively) correlating variables were psychological health and physical health with an exception of free-word association. The low correlating variables were social supports and lastly life stress with an exception of letter span. A general observation in this regard is that the one facet of memory 


\section{Memory in Old Age: Current Scenario in India}

viz., free word association was least correlating with psychological variables (Lalitha, 2000). Many studies reported that mental health may have a significant effect on learning and memory. It is evident that elderly exhibit higher levels of anxiety than young adults in testing and exhibit poor performance in memory tasks (Lalitha \& Jamuna, 2004a, 2004b, 2006).

Sometimes a really failing memory might taunt the person and make him believe that his/her memory 'is' failing and as a result his/her self-rated memory may also become poor. Similarly if self-perception of memory is bad, it might to that extent affect and reduce his/her self-esteem. Therefore, it should be born in mind that self rated memory and self esteem on the one hand and actual memory (real) performance on the other mutually interact and influencing each other. They could form a vicious circle. This goes to show that while interpreting the performance on memory tasks these factors should be reckoned.

It is very common that both old and young people often complain of a poor memory. Some find it very difficult to remember names or numbers and quickly forget them again and others find that they cannot recall old familiar names of people, things or places. Nevertheless, people also grow apprehensive about their poor memory, observing an increasing decline in mental powers or inability to keep pace with demands of their daily life.

It is evident from the researches that visualizing an object ensures acknowledging and creation of a visual understanding of the object. Visualization is an important component to all the taskspecific strategies, so it may be mastered before moving on to the next step of process. Association is the second strategy used in the memory interventions for the subject. Association is the incorporation of the object to be remembered into an individual's current form of work (or) with another item to be remembered. The strategy of association requires the individual to combine two or more things that the subjects want to remember in a meaningful way. Practice is an important component in mastering these strategies and achieving optimal performance.

Intervention results further showed that there were no pre and post test differences in control group, though there is a slight improvement in the performance of memory for digit backward and paired associates without any interventions, but the differences were not significant. The quantum of improvement after interventions was significantly high in experimental group (Lalitha, 2005). These results demonstrate the efficacy of interventions in improving memory for

digit span and verbal memory, between pre intervention and post intervention scores among the elderly in an Indian sample (Lalitha, 2004, 2005).

The findings of memory research have important implications for a country like India, where seventy million elderly live and few such studies have been carried out. Therefore, the application of large-scale interventions to improve the memory function in these elderly would go a long way in reducing their functional and psychological dependency. Thus, it has both practical as well as policy implications in the Indian setting. We need simple practical tips, based 
on studies, on how to improve memory function in the common elderly. Such tips are the need of the hour. All the activities of the elderly are based on an apparently failing memory. If only the practice of tips can bring a little improvement, it will instill more confidence, boost their selfimage, improve their social status and better their quality of life.

In summary, the aforementioned studies on memory researches in India indicate that the early studies concentrated on the development of memory scales for the Indian aged and the focus was shifted gradually on memory performance in various facets like working memory, semantic memory, and remote memory viz., episodic and autobiographical and pictorial memory. Also some studies have focused on psychosocial constituents (socio-demographic and psychological factors) of performance in the aged. There are only few studies on memory interventions and their efficacy. Though there are no contributions on theoretical perspectives on memory in the Indian aged yet the empirical studies are a good beginning and it is hoped that the theory based researches will ensure in due course.

\section{REFERENCES:}

Agrawal, R., \& Kumar, A. (1992). Everyday memory in adulthood. Psychological studies, 37(2-3), 161-172.

Anuradha, J., Amita, V., \& Verma, S.K. (1991). Some experience with a rapid test of mental functions in the elderly. In I.J. Prakash (Ed.,) Quality Aging (pp.179-185). Varanasi : Association of Gerontology (India), BHU.

Birren, J.E., \& Schaie, K.W. (1996). Handbook of the Psychology of Aging. New York: Van Nostrand Reinhold.

Bromley, D.B. (1958). Some effects of age on short- term learning and remembering. Journal of Gerontology, 13, 398-406.

Carol, R.A., \& Rabbit, P.M. (1991). The course and causes of cognitive changes with advancing age. Reviews in Clinical Gerontology (UK), 1 (1), 81-96.

Cavanaugh, J.C. (1997). Adult Development and Aging. 3rd Edn., New York: Thomson Pub. Inc.

Cavanaugh, J.C., \& Blanchard-Fields, F. (2002). Adult Age Development and Aging (IV Edition, pp.208-251). CA: Wadsworth Group.

Cohen, G. (1996). Memory and learning in normal aging. In R.T Woods (Ed.). Handbook of the Clinical Psychology of Ageing (pp.43-58), London: Wiley.

Dubey, B.L., \& Verma, S.K. (1991). Mental efficiency as a function of time in the elderly rural subjects. Journal of Personality and Clinical Studies, 7(1), 96-98.

Dubey, S. (1996). Measurement of cognitive dysfunctioning in elderly. In Vinodkumar (Ed.,) Ageing: Indian Perspective and Global Scenario. New Delhi: Vinodkumar.

Dubey, S. (1996). Measurement of cognitive dysfunctioning in elderly. In Vinodkumar (Ed.,) Ageing: Indian Perspective and Global Scenario. New Delhi: Vinodkumar

Dwivedi, M. (1988). Some studies on Everyday Memories. Ph.D., Dissertation, Bhopal University. Bhopal. 


\section{Memory in Old Age: Current Scenario in India}

Dwivedi, M., \& Misra, G. (1991). Memory beliefs and its correlates. Psychological studies, 36(3), 187- 191.

Gilbert, J.G. (1941). Memory loss in senescence. Journal of Abnormal and Social Psychology, 36, 73 - 86.

Gupta, Ashum., \& Kaur, Kalvinder, (1996). Episodic memory among the aged, 22(1\&2), Journal of Indian Academy of Applied Psychology, 107-113.

Gupta, Ashum., \& Srivatsava, S.K. (2000). Age deficits in discourse processing. 26(1\&2), Journal of Indian Academy of Applied Psychology, 119-123.

Hess, Thomas M. Hinson, Joey T. (2006). Age-Related Variation in the Influences of Aging Stereotypes on Memory in Adulthood. Psychology and Aging, 21(3),621-625

Howard, J.P. (2004). The Owner's Manual for the Brain: Everyday Applications from MindBrain Research. (pp.525-549, $5^{\text {th }}$ Edition). Austin: Bard Press.

in India: A review. Indian Psychological Abstracts and Reviews, 2 (2), 207-267.

Isaacs, B., \& Akhtar, A.J. (1972). The Set-Test. A rapid test of mental function in old people. Age and Ageing, 1, 222-226.

Jamuna, D., \& Ramamurti, P.V. (2000). Psychological Correlates of Long Lived Individuals. Project Report submitted to University Grants Commission, New Delhi.

Jamuna, D., Sujatharamamurti, \& Reddy, L.K. (1999). Correlates of Quality of Life among Indian elderly men and women. Project Report submitted Indian Council of Medical Research (ICMR), New Delhi.

Kausler, D.H. (1994). Learning memory in normal aging. San Diego, CA: Academic Press.

Kausler, D.H. (1994). Learning memory in normal aging. San Diego, CA: Academic Press.

Khan, M.I., \& Khan, S.H. (2002). Physiological and Cognitive changes associated with the elderly. In Akbar Hussain (Ed.) Healthy Ageing (pp. 40-52). Aligarh: Aligarh Muslim University.

Kohli, A., Banerjee, S.T., Verma, S.K., \& Nehra, R. (1992). Mental efficiency in elderly depressives. Indian Journal of Gerontology, 6 (3 \& 4), 93-97.

Kohli, A., Banerjee, S.T., Verma, S.K., \& Nehra, R. (1992). Mental efficiency in elderly depressives. Indian Journal of Gerontology, 6 (3 \& 4), 93-97.

Lalitha, K. (2000). Psycho-social Correlates of Memory in the Aged. Unpublished Doctoral Dissertation. Tirupati: S.V. University.

Lalitha, K. (2001). Memory Decline with Age- Myths and Realities. First National Conference of Academy of Psychologists, Tirupati, February, 7-9.

Lalitha, K. (2005). Enhancement of Memory in the Aged: An Interventional Study. Project Report submitted to ICMR, New Delhi.

Lalitha, K. (2009). Psychological correlates of Cognitive status in the Oldest old. Paper presented In International Colloquiqum on Oldest old. Centre for Gerontological studies ,Kerala, 8-11 Feb.,

Lalitha, K., \& Jamuna, D. (2004a). Memory status in the Indian Elderly. In P.V. Ramamurti and D. Jamuna (Eds.,). Handbook on Indian Gerontology (pp. 328-368). Delhi: Serial Publications. 


\section{Memory in Old Age: Current Scenario in India}

Lalitha, K., \& Jamuna, D. (2004b). Memory status in the Elderly and its Correlates: An Intervention Study. Indian Journal of Gerontology, 18 (1), 151-158.

Lalitha, K., \& Jamuna, D. (2006). Remote memory in the elderly and its impact on well being. Psychological studies, 50 (3), 275-279.

Park, D.C. (1997). Ageing and Memory: Mechanisms Underlying Age Differences in Performance. In Proc. of World Congress of Gerontology, Adelaide, Australia, 69-72.

Park, D.C., Smith, A.D., Lautenschlager, G., Earles, J.L., Frieske, D., Zwahr, M., \& Gaines, C.L. (1996). Mediators of long-term memory performance across the life span. Psychology and Aging, 11, 621-637.

Perlmutter, M. (1986). A life-span view of memory. In P.B. Baltes and D. Featherman (Eds.). Life Span Development and Behaviour, 7, San Diego, CA : Academic Press.

Pershad, D. (1976). Interdependence of memory and intelligence. Indian Journal of Psychology, 51, 333-338.

Pershad, D. (1979a). Construction and Standardization of a Clinical test of Memory. Agra: National Psychological Corporation.

Pershad, D. (1979b). Forgetting and new learning deficit in elderly subjects. Journal of Psychological Researchers, 23 (2), 73 - 75.

Pershad, D., \& Wig, N.N. (1976). A battery of simple test of memory for use in India. Neurology India, 24, 86-93.

Pershad, D., \& Wig, N.N. (1977). PGI memory scale. A normative study on elderly subjects. Indian Journal of Clinical Psychology, 4, 6-8.

Poon, L.W. (1985). Differences in human memory with aging: Nature, Causes, and Clinical Implications. In J.E. Birren and K.W. Schaie (Eds.), Handbook of Mental Health and Aging. Englewood Cliffs, N.J: Prentice-Hall.

Psychology Today, (1993). How Mind Ages, 26 (6), 38-42.

Ramamurti, P.V. (1978). On Second Childishness : Reflections of a Psychologist. In N. Subbu Reddiar (ed). Studies on Arts and Sciences (pp. 236-240). Madras: Ram Bros.

Ramamurti, P.V. (1990). Cognitive decline in old age. In G.S. Koshe, Usha Khire, Bala Kulkarni \& Chature Damle (eds.). Proceedings of the National Seminar on the IQ controversy. Jnana Prabodhini Institute of Psychology, Pune.

Ramamurti, P.V., \& Jamuna, D. (1984). Psychological research on the aged in India. Journal of Anthropological Society of India, 19 (3), 269-286.

Ramamurti, P.V., \& Jamuna, D. (1993). Psychological Dimensions of Aging in India. Indian Jr. of Social Sciences, 6(4): 309-331.

Ramamurti, P.V., \& Jamuna, D. (1995). Perspectives of Geropsychology

Salthouse, T.A. (1994). How many causes are there of aging-related decrements in cognitive functioning? Developmental Review, 24 (4), 413-437.

Salthouse, T.A., \& Skovernek, E. (1992). Within -Context assessment of working memory. The Journal of Gerontology, 47, 110-129.

Sharma, R.C., Bansal, A., \& Bhatt, S.C. (1992). Language loss in aging. Indian Journal of Gerontology, 6 (3 \& 4), 98-105. 
Sharma, R.C., Bansal, A., \& Bhatt, S.C. (1992). Language loss in aging. Indian Journal of Gerontology, 6 (3 \& 4), 98-105.

Smith, A.D. (1996). Memory In J.E. Birren, K.W., Schaie, R.P. Abeles, M. Gatz, \& T.A. Salthouse (Eds.) Handbook of the Psychology of Aging ( $4^{\text {th }}$ ed., pp.236-250). Sun Diego, CA : Academic Press.

Verma, S.K., \& Pershad, D. (1996). Self - Help Groups and Cognitive Retraining in the elderly. Research and Development Journal, 3(1), 28-36.

Verma, S.K., Kohli, A., Banerjee, S.T. \& Nehra, R. (1992). A normative study of mental efficiency in old age. Indian Journal of Gerontology, 6(1\&2), 20-27.

Whitbourne, S.K. (2005). Adult Development and Aging: Bio- Psychosocial Perspectives (II Edition). Wiley: John Wiley \& Sons, Inc.

Willingham, D.T. (2004). Cognition the Thinking Animal ( $2^{\text {nd }}$ ed.).Upper saddle river, NJ: Prentice-Hall.

Wythe, W.L., \& Anderson, S.D. (1997). Differential age-related processing limitations in recall and recognition tasks. Psychology and Aging, 12 (2), 216-224. 